\title{
Patient-reported barriers to osteoporosis therapy
}

\author{
Brianna R. Lindsay ${ }^{1}$ - Temitope Olufade ${ }^{1}$ - Jennifer Bauer ${ }^{2}$ - Jane Babrowicz ${ }^{2}$. \\ Rebecca Hahn ${ }^{2}$
}

Received: 7 January 2016 / Accepted: 10 April 2016 /Published online: 29 April 2016

(C) The Author(s) 2016. This article is published with open access at Springerlink.com

\begin{abstract}
Summary We investigated reasons for non-treatment of osteoporosis and discontinuation of osteoporosis therapy. Barriers to treatment include patients' preference for alternative treatments and a fear of possible side effects. Side effects are a common reason for treatment discontinuation, and they may be associated with a lack of willingness to restart treatment. Purpose/introduction Osteoporosis patients commonly cite treatment-related side effects, or the fear thereof, as a reason for discontinuing or not initiating anti-osteoporosis medications. The purpose of this study was to investigate, from the patient's perspective, reasons for (i) non-treatment of osteoporosis and (ii) discontinuation of osteoporosis therapy.

Methods This was an internet-based survey of postmenopausal women in the USA who self-reported having been diagnosed with osteoporosis. Respondents were recruited from consumer research panels and received nominal compensation. Results Within the surveyed population $(N=1407), 581$ patients were currently being treated, 503 had never been treated, and 323 had previously been treated. Among patients never treated for osteoporosis, the highest ranking reasons for nontreatment were the use of alternative treatments such as overthe-counter vitamins/supplements (57.5\% of respondents) and fear of side effects $(43.9 \%)$. Among previously treated
\end{abstract}

Electronic supplementary material The online version of this article (doi:10.1007/s11657-016-0272-5) contains supplementary material, which is available to authorized users.

Brianna R. Lindsay

Brianna_lindsay@merck.com

1 Center for Observational and Real-World Evidence, Merck \& Co. Inc., Kenilworth, NJ, USA

2 Nielsen, New York, NY, USA patients, frequent reasons for discontinuation included the direction of the physician (41.2\% of respondents), concerns about long-term safety (30.3\%), and the experience of side effects $(29.8 \%)$. When asked about their willingness to restart their osteoporosis medication, previously treated patients who were not willing $(N=104)$ to restart had a higher frequency of experiencing side effects (44.2 versus $20.5 \%$ of those willing; $P<0.001)$.

Conclusions From the osteoporosis patient's perspective, barriers to prescription treatment include a preference for alternative, non-prescription treatments and a fear of possible side effects. Side effects are one of the most common reasons for discontinuing osteoporosis medications, and they appear to be associated with a lack of willingness to restart treatment.

Keywords Osteoporosis, postmenopausal/drug therapy · Medication adherence $\cdot$ Patient compliance $\cdot$ Persistence . Health knowledge, attitudes, practice $\cdot$ Health surveys

\section{Introduction}

The estimated prevalence of osteoporosis among US women aged 50 and older, based on bone mineral density of the total hip or of the total hip or spine, was $14-16 \%$ in 2010 [1]. The National Osteoporosis Foundation recommends pharmacologic treatment in patients with low bone mineral density, corresponding to $T$ scores $\leq-2.5$, at the femoral neck, total hip, or lumbar spine [2]. However, despite this recommendation, substantial under-treatment of osteoporosis in postmenopausal US women has been observed [3, 4]. A 2014 retrospective cohort study of US women aged $\geq 55$ with a claimsdocumented diagnosis of osteoporosis found that $64.3 \%$ of patients did not receive osteoporosis treatment within 1 year after the diagnosis [3]. 
For those patients initiating therapy, discontinuation is commonly reported. A retrospective cohort study on US women aged $\geq 55$ years initiating osteoporosis therapy reported discontinuation rates of 45,58 , and $70 \%$ at 6,12 , and 24 months, respectively [5]. Similar 12-month discontinuation rates were reported in other US studies [6, 7]. Many discontinuations occur because of side effects [8], but some may occur in the context of a drug holiday, that is, an intentional discontinuation of medication recommended by national guidelines for patients with satisfactory response to longterm therapy [9]. Whether patients reinitiate therapy after discontinuation has been addressed by several US studies, with rates of reinitiation ranging from $30 \%$ within 6 months to $50 \%$ within 2 years $[5,6,10,11]$.

Previous studies have identified several patient characteristics, e.g., body mass index [12] and comorbidities [13], that are associated with non-treatment. Similarly, correlates of reinitiation of therapy have been identified, including longer duration of treatment before the discontinuation, younger age, and a history of fracture [5, 10]. This study was designed to complement these findings by assessing the reasons for non-treatment and the reasons for discontinuation from the patient's perspective, with an emphasis on how the reasons for discontinuation interact with a patient's willingness to reinitiate therapy.

\section{Methods}

\section{Study design and data source}

This was a cross-sectional online survey of women in the USA who participated in online consumer panels, primarily Harris Poll Online. This consumer panel consists of adults, aged 18 or older, who have self-selected into the panel because they are interested in participating in online surveys. The survey was conducted between July 7 and July 25, 2014. Eligible participants received an invitation via e-mail with information about accessing the online survey. Potential participants were offered compensation in the form of panel points, which could be redeemed for a nominal monetary reward.

\section{Survey participants}

Postmenopausal US women aged $\geq 40$ who self-reported being diagnosed with osteoporosis were eligible for inclusion. Participants were classified by self-report as currently treated, never treated, and previously treated. Possible treatments included both oral and injectable prescription medications.

\section{Survey content}

The survey was pre-tested among a small group of about 12 adults in order to test the survey with live respondents and allow the added benefit of qualitative insight into patient perceptions and attitudes. This ensured that the survey was clear and concise while capturing the most relevant dimensions necessary for comprehensive analysis (see Appendix for survey).

Respondents were asked about their current and past osteoporosis treatments, their reasons for not starting or for discontinuing treatment, their interactions with their treating physicians, and, if previously treated, their willingness to restart therapy. Demographic information was also collected, including comorbidities, history of fractures, race/ethnicity, education, and health insurance coverage.

Never-treated patients were asked to select all their reasons for remaining untreated and to rank their top three reasons. Possible choices included employing alternative treatments or implementing lifestyle changes, various beliefs about osteoporosis or medication, concerns about safety, and cost issues. Previously treated patients were asked to select all their reasons for discontinuing treatment and to rank their top three reasons. Possible choices included concerns about side effects, cost and insurance coverage, and dosing or regimen. Previously treated patients were also queried about their willingness to restart the medication originally used to treat osteoporosis. Responses included not at all willing, somewhat willing, willing, very wiling, and extremely willing. All patients were asked to assess how often statements about their interactions with their treating physician were true. Statements focused on the relationship and trust between the patient and their physician. Responses included never, rarely, sometimes, often, and always.

\section{Data analysis}

A total sample size of 1400 was predicted to be sufficient to detect statistically significant differences between the patient subgroups. In order to ensure an adequate sample size for analyses, quotas were set for the three categories of respondents based on prevalence estimates from previous studies: $N=500$ for never treated ( $\sim 35 \%), N=320$ for previously treated ( $23 \%$ ), and $N=580$ for currently treated patients ( $\sim 2 \%)$. Participants were continuously recruited until quotas were met. The analyses were primarily descriptive, with bivariate statistical tests used as needed. Descriptive data for each of the three groups of patients are presented as numbers and percentages for categorical variables or as means and standard deviations for continuous variables. Patient characteristics were compared across all three treatment groups. Perceptions of the physician-patient relationship among currently treated patients were compared with those of never 
treated and previously treated patients. Reasons for discontinuation were compared between patients not willing to restart therapy and somewhat to extremely willing to restart therapy. Throughout the analyses, continuous variables were compared with $t$ tests and categorical variables with chi-square tests or analysis of variance (ANOVA) techniques, and $P$ values $<0.05$ were considered statistically significant.

\section{Results}

\section{Characteristics of the study population}

A total of 1407 osteoporosis patients participated in the survey (Table 1). The mean age of all patients was 64 years. Most patients had at least some college or graduate schooling ( $71.3 \%$ total), had drug coverage through their health insurance $(89.0 \%)$, and reported having had a DEXA scan $(83.5 \%)$. The majority of patients included in this study were white (93.2\%; data not shown). Furthermore, patients were almost equally distributed between regions of the USA with $36.2 \%$ in the south, $23.5 \%$ in the midwest, $20.3 \%$ in the northeast, and $20.0 \%$ in the west (data not shown).

Within the surveyed population, 581 patients were currently being treated, 503 had never been treated, and 323 had previously been treated (Table 1). Currently treated patients more frequently had graduate level education (22.7 versus $14.5 \%$ for never-treated and $21.1 \%$ for previously treated patients; $P=0.004$ ), had drug coverage through insurance (93.6 versus $83.9 \%$ for never-treated and $88.5 \%$ for previously treated patients; $P<0.001$ ), and reported having had a DEXA scan (89.2 versus $74.0 \%$ for never-treated and $88.2 \%$ for previously treated patients; $P<0.001$ ).

\section{Reasons for non-treatment}

Among patients never treated for osteoporosis, the highestranking reasons for non-treatment were use of over-thecounter vitamins/supplements instead (57.5\% of respondents), fear of side effects (43.9\% of respondents), and

Table 1 Baseline characteristics of survey respondents

\begin{tabular}{|c|c|c|c|c|c|}
\hline & $\begin{array}{l}\text { Total } \\
N=1407\end{array}$ & $\begin{array}{l}\text { Never treated } \\
N=503\end{array}$ & $\begin{array}{l}\text { Previously treated } \\
N=323\end{array}$ & $\begin{array}{l}\text { Currently treated } \\
N=581\end{array}$ & $P$ value \\
\hline Age, mean $(\mathrm{SD})$ years & $64(9.1)$ & $62(8.7)$ & $68(8.3)$ & $63(9.2)$ & $<0.001$ \\
\hline $\begin{array}{l}\text { Years since diagnosis, } \\
\text { mean }(\mathrm{SD})\end{array}$ & $7.8(6.7)$ & $6.5(6.1)$ & $10.8(7.5)$ & $7.2(6.3)$ & $<0.001$ \\
\hline \multicolumn{6}{|l|}{ Education } \\
\hline High school graduate or less & $395(28.1)$ & $163(32.4)$ & $85(26.3)$ & $147(25.3)$ & \multirow[t]{3}{*}{0.004} \\
\hline Some college or college graduate & $730(51.9)$ & $262(52.2)$ & $169(52.3)$ & $299(51.5)$ & \\
\hline Graduate school & $273(19.4)$ & $73(14.5)$ & $68(21.1)$ & $132(22.7)$ & \\
\hline \multicolumn{6}{|l|}{ Drug coverage } \\
\hline Yes, through my health insurance & $1252(89.0)$ & $422(83.9)$ & $286(88.5)$ & $544(93.6)$ & \multirow[t]{4}{*}{$<0.001$} \\
\hline $\begin{array}{l}\text { Yes, through a patient assistance } \\
\text { or co-pay card }\end{array}$ & $49(3.5)$ & $19(3.8)$ & $14(4.3)$ & $16(2.8)$ & \\
\hline No & $95(6.8)$ & $56(11.1)$ & $22(6.8)$ & $17(2.9)$ & \\
\hline Not sure & $11(0.8)$ & $6(1.2)$ & $1(0.3)$ & $4(0.7)$ & \\
\hline \multicolumn{5}{|l|}{ General health } & \multirow[t]{4}{*}{0.004} \\
\hline Poor/fair & $464(33.0)$ & $192(38.2)$ & $93(28.8)$ & $179(30.8)$ & \\
\hline Good & $486(34.5)$ & $176(35.0)$ & $119(36.8)$ & $191(32.9)$ & \\
\hline Very good/excellent & $457(32.5)$ & $135(26.8)$ & $111(34.4)$ & $211(36.3)$ & \\
\hline $\begin{array}{l}\text { Number of poor physical health days } \\
\text { during past } 30 \text { days, mean (SD) }\end{array}$ & $7.27(10.01)$ & $8.09(10.22)$ & $6.42(9.73)$ & $7.03(9.96)$ & 0.095 \\
\hline $\begin{array}{l}\text { Number of poor mental health days } \\
\text { during past } 30 \text { days, mean (SD) }\end{array}$ & $5.14(8.57)$ & $6.14(9.31)$ & $5.00(8.58)$ & 4.35 (7.79) & 0.001 \\
\hline $\begin{array}{l}\text { Number of days poor physical or } \\
\text { mental health prevented usual } \\
\text { activities during past } 30 \text { days, mean (SD) }\end{array}$ & $5.32(9.04)$ & $6.46(9.75)$ & $4.58(8.57)$ & $4.75(8.55)$ & 0.002 \\
\hline DEXA scan & $1175(83.5)$ & $372(74.0)$ & $285(88.2)$ & $518(89.2)$ & $<0.001$ \\
\hline Broke a bone after age 45 & $539(38.3)$ & $177(35.2)$ & $130(40.2)$ & $232(39.9)$ & 0.183 \\
\hline Fell in the past 12 months & $466(33.1)$ & $177(35.2)$ & $106(32.8)$ & $183(31.5)$ & 0.433 \\
\hline
\end{tabular}

Values are presented as $N(\%)$ unless indicated otherwise

$D E X A$ dual X-ray absorptiometry, $S D$ standard deviation 
implementation of lifestyle changes instead $(37.8 \%$ of respondents; Fig. 1). Other common reasons included the belief that osteoporosis is not serious enough to require prescription medication (24.3\% of respondents) and concerns about the cost of medication (24.1\% of respondents). Never-treated patients were less likely than currently treated patients to feel understood by their physicians $(77$ versus $83 \% ; P<0.05)$ and to have "a lot of trust" in their physicians ( 81 versus $87 \%$; $P<0.05$; Fig. 2).

\section{Reasons for discontinuation}

Among previously treated patients, the most frequent reason for discontinuation was the direction of the physician $(41.2 \%$ of respondents; Fig. 3). Concerns about long-term safety $(30.3 \%)$ and the experience of side effects $(29.7 \%)$ also ranked high among the reasons for discontinuation. Previously treated patients were less likely than currently treated patients to feel understood by their physicians ( 77 versus $83 \% ; P<0.05)$ and less likely to say that their physician expressed confidence in their ability to take the medication as prescribed (61 versus $71 \% ; P<0.05$; Fig. 2).

\section{Willingness to reinitiate treatment}

Patients not at all willing $(N=104)$ differed from those somewhat to extremely willing $(N=195)$ to restart their medication in terms of their reasons for discontinuation (Table 2). Among these reasons, patients who were not willing to restart had a higher frequency of experiencing side effects (44.2 versus $20.5 \%$ of those willing; $P<0.001)$, had more often heard negative news about osteoporosis medications (33.7 versus $20.5 \%$ of those willing; $P=0.013$ ), and more frequently had concerns about the long-term safety of their osteoporosis medications (40.4 versus $25.6 \%$ of those willing; $P=0.009$ ). Patients somewhat to extremely willing to restart therapy were more likely to have discontinued for reasons of cost than those not willing to restart ( 18.5 versus $8.7 \% ; P=0.024)$.

\section{Discussion}

This study was designed to assess patients' reasons for nontreatment of osteoporosis among patients who were never treated and reasons for discontinuation of osteoporosis therapy among those who had been treated previously. Currently and previously treated patients were older, more frequently had drug coverage through insurance, and reported better general health and fewer days of poor physical or mental health during the past 30 days than never-treated patients. These results are consistent with a US retrospective analysis that found that older age, better physical functioning, and prescription insurance coverage were among the patient characteristics associated with receiving osteoporosis therapy [13].

Among patients never treated for osteoporosis in the current study, the highest ranking reasons for non-treatment were the use of alternative treatments such as over-the-counter vitamins/supplements and the fear of side effects. The latter result agrees with the findings of $\mathrm{Yu}$ et al., who found that among US osteoporotic women aged 55 and older, the primary reason for not initiating osteoporosis therapy was concern over side effects (77.3\% of survey respondents) [4]. Similarly, in a survey that analyzed factors associated with the decision of US women to initiate osteoporosis therapy, respondents who did not initiate prescription medication for osteoporosis were more likely to worry about the side effects of taking
Fig. 1 Reasons for not initiating osteoporosis treatment among untreated patients. $O P$ osteoporosis. $N=503$

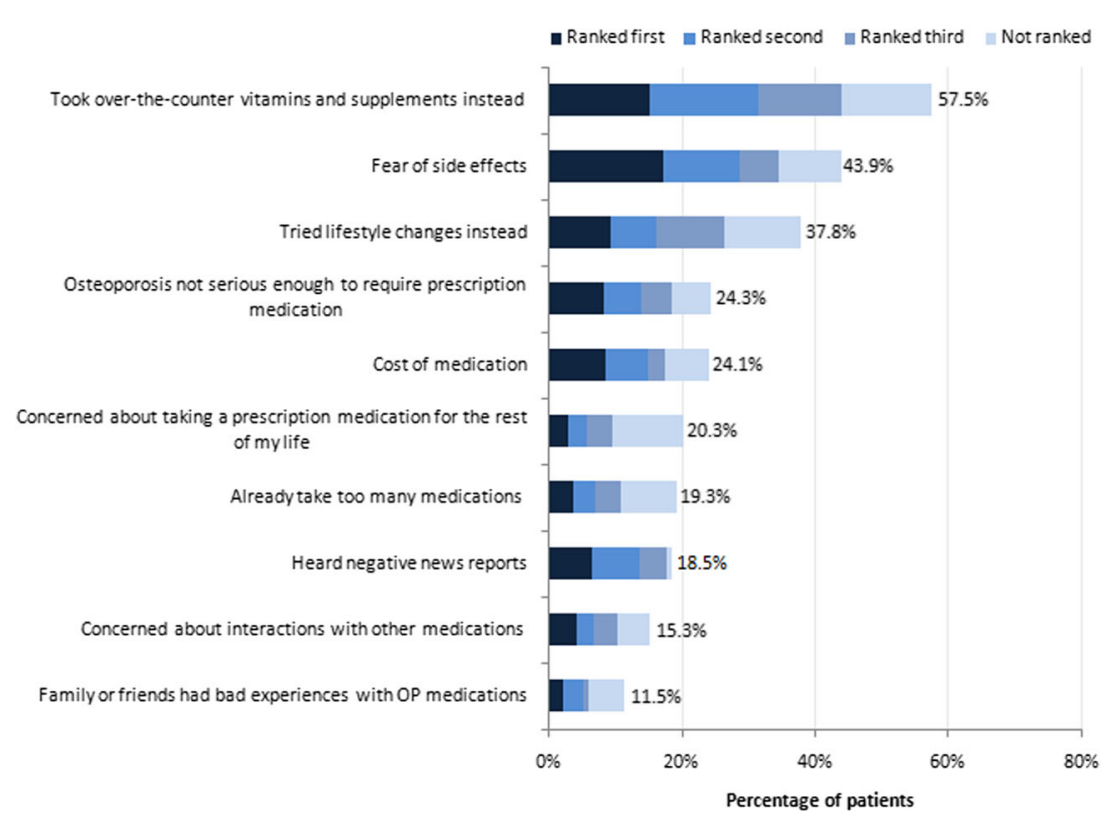


Fig. 2 Perceptions of the physician-patient relationship. $O P$ osteoporosis. The bars show the percentage of women who responded either "often" or "always" when asked to indicate how often each statement was true regarding visits with the physician who treated their osteoporosis over the past 12 months. $* P<0.05$ between currently treated and nevertreated patients. ${ }^{\dagger} P<0.05$ between currently treated and previously treated patients

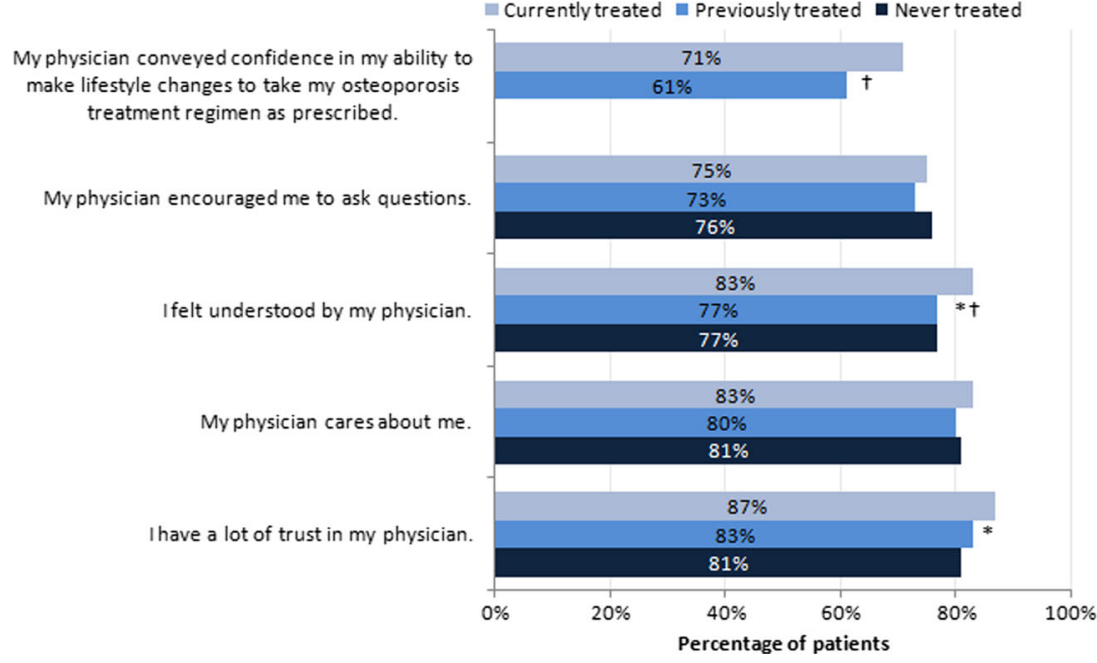

osteoporosis medication and more likely to agree with the statement, "I can take care of my osteoporosis without medication" [14]. In addition, respondents who initiated osteoporosis prescription medication believed more strongly in the effectiveness of medication, while non-initiators reported having more distrust of medications [14]. In our analysis, fear of side effects was the most frequently first-ranked reason for non-treatment (see Fig. 1), and this fear may have acted as a driver for women to try alternative therapies, thus resulting in our finding that over half of the women included in this study preferred taking over-the-counter vitamins and supplements for osteoporosis.

The results of our survey show that the cost of medication is a barrier to initiating osteoporosis therapy among $24.1 \%$ of the surveyed population. These results are consistent with those of Yu et al. Among the surveyed women, $34.1 \%$ cited the cost of medication as their reason for not initiating treatment [4]. In addition, in a study of osteoporotic US women aged 40 and older, out-of-pocket spending on prescriptions as a proportion of income was found to be a significant predictor of receiving a prescription therapy for osteoporosis or osteopenia $(P=0.01)$ [13].

In the current survey, the most frequent reasons for discontinuation among previously treated patients included the direction of the physician, concerns about long-term safety, and the experience of side effects. The fact that some physicians are directing their patients to discontinue treatment is consistent with national guidelines that allow for a drug holiday [9], or it may be that physicians incorporate flexibility into the regimens of patients experiencing medication-related adverse effects. Experiencing side effects is a commonly cited reason for discontinuing osteoporosis therapy, as shown by health care and claims database analyses [6, 7] and telephone and questionnaire-based surveys [8, 15]. Regarding long-term safety profiles, patients taking bisphosphonates may be aware of reports of infrequent occurrences of renal toxicity, atypical subtrochanteric and femoral shaft fractures, osteonecrosis
Fig. 3 Reasons for discontinuing osteoporosis therapy among previously treated patients. $N=323$

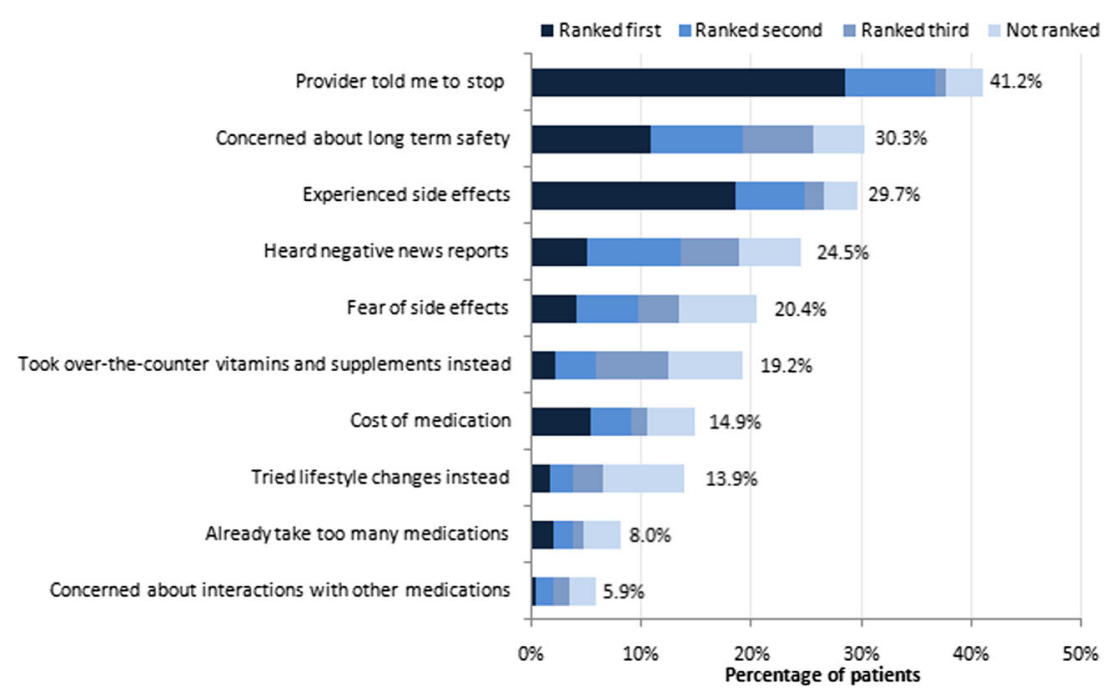


Table 2 Reasons for discontinuation among patients willing or not willing to restart therapy

\begin{tabular}{|c|c|c|c|}
\hline Reason for discontinuation & $\begin{array}{l}\text { Not willing } \\
N=104\end{array}$ & $\begin{array}{l}\text { Somewhat to extremely } \\
\text { willing } N=195\end{array}$ & $P$ value \\
\hline \multicolumn{4}{|l|}{ Perceived side effects } \\
\hline I experienced side effects & $46(44.2)$ & $40(20.5)$ & $<0.001$ \\
\hline $\begin{array}{l}\text { I heard negative news reports } \\
\text { about OP medications }\end{array}$ & $35(33.7)$ & $40(20.5)$ & 0.013 \\
\hline Fear of side effects & $25(24.0)$ & $35(17.9)$ & 0.211 \\
\hline $\begin{array}{l}\text { I knew family or friends who } \\
\text { had bad experiences with OP medications }\end{array}$ & $10(9.6)$ & $5(2.6)$ & 0.008 \\
\hline \multicolumn{4}{|l|}{ Safety } \\
\hline I was concerned about long-term safety & $42(40.4)$ & $50(25.6)$ & 0.009 \\
\hline $\begin{array}{l}\text { I was concerned about interactions } \\
\text { with other medications }\end{array}$ & $4(3.8)$ & $14(7.2)$ & 0.248 \\
\hline \multicolumn{4}{|l|}{ Cost/coverage } \\
\hline Cost of medication & $9(8.7)$ & $36(18.5)$ & 0.024 \\
\hline It wasn’t covered by my insurance & $2(1.9)$ & $14(7.2)$ & 0.054 \\
\hline \multicolumn{4}{|l|}{ Dosing/regimen } \\
\hline $\begin{array}{l}\text { My health care provider told me to } \\
\text { stop taking the OP prescription }\end{array}$ & $43(41.3)$ & $80(41.0)$ & 0.957 \\
\hline I felt like I already take too many medications & $7(6.7)$ & $16(8.2)$ & 0.649 \\
\hline Inconvenient/complex dosing & $1(1.0)$ & $2(1.0)$ & - \\
\hline Problems remembering to take it & $1(1.0)$ & $11(5.6)$ & 0.050 \\
\hline \multicolumn{4}{|l|}{ Beliefs about osteoporosis/medication } \\
\hline $\begin{array}{l}\text { I did not think the prescription would } \\
\text { work/was effective }\end{array}$ & $6(5.8)$ & $11(5.6)$ & 0.9636 \\
\hline $\begin{array}{l}\text { I did not believe that my osteoporosis } \\
\text { was serious enough to take a medication }\end{array}$ & $3(2.9)$ & $12(6.2)$ & 0.2174 \\
\hline I did not understand the purpose of the medication & $0(0.0)$ & $3(1.5)$ & - \\
\hline I did not believe that my OP was life threatening & $4(3.8)$ & $12(6.2)$ & 0.3984 \\
\hline I did not think that I needed OP medication & $4(3.8)$ & $9(4.6)$ & 0.7561 \\
\hline \multicolumn{4}{|l|}{ Alternatives } \\
\hline $\begin{array}{l}\text { I decided to take over-the-counter vitamins } \\
\text { and supplements for my osteoporosis instead } \\
\text { of prescription medication }\end{array}$ & $22(21.2)$ & $32(16.4)$ & 0.3098 \\
\hline $\begin{array}{l}\text { I decided to try lifestyle changes instead of } \\
\text { taking OP medications }\end{array}$ & $20(19.2)$ & $22(11.3)$ & 0.0596 \\
\hline
\end{tabular}

Values are presented as $N(\%)$. Italicized data indicate statistically significant differences between patients not willing or at all willing to restart treatment $O P$ osteoporosis

of the jaw, and, with intravenous formulations, influenzalike symptoms [16, 17]. An additional reason for discontinuation reported in this study was the cost of medication. This result is consistent with the findings of an Italian survey of postmenopausal women in which roughly $10 \%$ of participants reported cost as a reason for discontinuation [18].

In the current study, $65.2 \%$ of patients (195 of the 299 who answered this survey question) were somewhat to extremely willing to restart therapy. This value is higher than the rates of reinitiation reported in other observational studies $[5,6,10,11]$, perhaps because there is a difference between willingness to restart therapy and actually filling a prescription. Our results showed that patients not willing to restart osteoporosis treatment were more likely to have discontinued because of side effects and concerns about safety, compared to patients who were willing to restart therapy. These findings provide a link between reasons for discontinuation and predictors of reinitiation and offer insight into the known correlates of reinitiation of therapy. For example, women with side effects and women concerned about the long-term safety of their treatment will likely discontinue sooner, and early discontinuation is predictive of a lack of reinitiation of therapy [5, 10].

These findings have implications for insurance coverage of osteoporosis therapy. In order to manage pharmacy costs, managed care organizations may implement step-therapy restrictions in which patients are required to try generic, payer- 
preferred treatments before being reimbursed for a more expensive or branded medication. In many cases, this may mean that patients need to restart their previous medication in order to get a different prescription. Our study shows that treatment side effects may affect patient's willingness to participate in the step-therapy process.

The primary limitation of this study is its potential lack of generalizability, because the survey population was derived from a consumer panel and may differ from patient populations derived from clinics or claims databases. In addition, the survey was conducted online which may also impact the generalizability. The cross-sectional survey design is limited by the accuracy of patient recall and reporting bias. For example, the diagnosis of osteoporosis in this study was based on selfreport and not confirmed by medical records or physician contact and thus was subject to error. The lack of precision regarding the diagnosis of osteoporosis may explain why one quarter of patients included in our survey believed that osteoporosis was not serious enough to require a prescription medication. In addition, when participants were asked if they had ever had a BMD test or DEXA scan, recall bias and lack of knowledge of terminology could have impacted their response to this question. Also, in classifying patients as never treated, there was no distinction between patients who never received a prescription and those who received one but did not fill it. In this survey, no distinctions were made between types of osteoporosis treatments, so we could not determine whether patients taking oral versus injectable therapies or bisphosphonates versus non-bisphosphonates would have had substantially different results. In addition, we did not collect data on the time from osteoporosis diagnosis to medication initiation. This data may have helped determine whether patients that were never treated were simply not yet treated. Finally, the effect of confounders on the willingness to restart therapy was not assessed in this study.

\section{Conclusion}

The results of this study show that barriers to osteoporosis therapy include a preference for alternative, non-prescription treatments and a fear of possible side effects. Furthermore, side effects are one of the most common reasons for discontinuing osteoporosis medications, and they appear to be associated with a lack of willingness to restart treatment.

Acknowledgments The authors thank Anna Kaufman, MPH, and Melissa Stauffer, $\mathrm{PhD}$, in collaboration with SCRIBCO, for the medical writing assistance.

\section{Compliance with ethical standards}

Conflict of interest BRL is an employee of Merck \& Co., Inc. TO was an employee of Merck \& Co., Inc. at the time of the study. J. Bauer, J.
Babrowicz, and $\mathrm{RH}$ are employees of Nielsen, which received funding from Merck \& Co., Inc. for the participation in the study.

The study was funded by Merck \& Co., Inc.

Open Access This article is distributed under the terms of the Creative Commons Attribution 4.0 International License (http:// creativecommons.org/licenses/by/4.0/), which permits unrestricted use, distribution, and reproduction in any medium, provided you give appropriate credit to the original author(s) and the source, provide a link to the Creative Commons license, and indicate if changes were made.

\section{References}

1. Wade SW, Strader C, Fitzpatrick LA, Anthony MS, O'Malley CD (2014) Estimating prevalence of osteoporosis: examples from industrialized countries. Arch Osteoporos 9: 182. doi:10.1007/s11657-014-0182-3

2. National Osteoporosis Foundation (2014) Clinician's guide to prevention and treatment of osteoporosis. National Osteoporosis Foundation. http://nof.org/files/nof/public/ content/file/2791/upload/919.pdf. Accessed August 182015

3. Siris ES, Modi A, Tang J, Gandhi S, Sen S (2014) Substantial under-treatment among women diagnosed with osteoporosis in a US managed-care population: a retrospective analysis. Curr Med Res Opin 30:123-130. doi:10.1185/03007995.2013.851074

4. Yu J, Brenneman SK, Sazonov V, Modi A (2015) Reasons for not initiating osteoporosis therapy among a managed care population. Patient Prefer Adherence 9:821-830. doi:10.2147/ppa.s81963

5. Balasubramanian A, Brookhart MA, Goli V, Critchlow CW (2013) Discontinuation and reinitiation patterns of osteoporosis treatment among commercially insured postmenopausal women. Int J Gen Med 6:839-848. doi:10.2147/ijgm.s36944

6. Lo JC, Pressman AR, Omar MA, Ettinger B (2006) Persistence with weekly alendronate therapy among postmenopausal women. Osteoporos Int 17:922-928. doi:10.1007/s00198-006-0085-2

7. Yun H, Curtis JR, Guo L, Kilgore M, Muntner P, Saag K, Matthews R, Morrisey M, Wright NC, Becker DJ, Delzell E (2014) Patterns and predictors of osteoporosis medication discontinuation and switching among Medicare beneficiaries. BMC Musculoskelet Disord 15:112. doi:10.1186/1471-247415-112

8. Tosteson AN, Grove MR, Hammond CS, Moncur MM, Ray GT, Hebert GM, Pressman AR, Ettinger B (2003) Early discontinuation of treatment for osteoporosis. Am J Med 115:209-216

9. Watts NB, Bilezikian JP, Camacho PM, Greenspan SL, Harris ST, Hodgson SF, Kleerekoper M, Luckey MM, McClung MR, Pollack RP, Petak SM, Force AOT (2010) American association of clinical endocrinologists medical guidelines for clinical practice for the diagnosis and treatment of postmenopausal osteoporosis. Endocr Pract 16(Suppl 3):1-37

10. Brookhart MA, Avorn J, Katz JN, Finkelstein JS, Arnold M, Polinski JM, Patrick AR, Mogun H, Solmon DH (2007) Gaps in treatment among users of osteoporosis medications: the dynamics of noncompliance. Am J Med 120:251-256. doi:10.1016/j. amjmed.2006.03.029

11. Tosteson AN, Do TP, Wade SW, Anthony MS, Downs RW (2010) Persistence and switching patterns among women with varied osteoporosis medication histories: 12-month results from POSSIBLE US. Osteoporos Int 21:1769-1780. doi:10.1007/s00198-009-1133-5

12. Asche C, Nelson R, McAdam-Marx C, Jhaveri M, Ye X (2010) Predictors of oral bisphosphonate prescriptions in post-menopausal women with osteoporosis in a real-world 
setting in the USA. Osteoporos Int 21:1427-1436. doi:10. 1007/s00198-009-1079-7

13. Meadows ES, Mitchell BD, Bolge SC, Johnston JA, Col NF (2012) Factors associated with treatment of women with osteoporosis or osteopenia from a national survey. BMC Womens Health 12:1. doi: 10.1186/1472-6874-12-1

14. Yood RA, Mazor KM, Andrade SE, Emani S, Chan W, Kahler KH (2008) Patient decision to initiate therapy for osteoporosis: the influence of knowledge and beliefs. J Gen Intern Med 23:1815-1821. doi:10.1007/s11606-0080772-0

15. Woo C, Gao G, Wade S, Hochberg MC (2010) Gastrointestinal side effects in postmenopausal women using osteoporosis therapy: 1- year findings in the POSSIBLE US study. Curr Med Res Opin 26:1003-1009. doi:10.1185/03007991003633603

16. Strampel W, Emkey R, Civitelli R (2007) Safety considerations with bisphosphonates for the treatment of osteoporosis. Drug Saf 30:755-763

17. Hollick RJ, Reid DM (2011) Role of bisphosphonates in the management of postmenopausal osteoporosis: an update on recent safety anxieties. Menopause Int 17:66-72. doi:10.1258/mi.2011. 011014

18. Rossini M, Bianchi G, Di Munno O, Giannini S, Minisola S, Sinigaglia L, Adami S (2006) Determinants of adherence to osteoporosis treatment in clinical practice. Osteoporos Int 17:914-921. doi:10.1007/s00198-006-0073-6 